\title{
Synthesis, Structure and Application of Fluorine-Graphite Intercalation Compound
}

\author{
Tsuyoshi Nakajima \\ (Received January 24, 1992) \\ Division of Molecular Engineering, \\ Graduate School of Engineering, \\ Kyoto University, Sakyo-ku, \\ Kyoto 606 , Japan
}

\begin{abstract}
The synthesis, electrical conductivity and stability of fluorine-intercalated carbon fibers have been summarized. Stage 1 to 4 compounds, $\mathrm{C}_{3} \mathrm{~F}-\mathrm{C}_{16} \mathrm{~F}$, are synthesized according to the crystallinity of host carbon fibers and reaction conditions. With increasing crystallinity of carbon fiber, and with increasing acidity of a coexisting solid fluoride and amount of coexisting HF, fluorine intercalation is facilitated. The highest electrical conductivities were (8-9) $\times 10^{3}, 2.4 \times 10^{4}$ and $1.1 \times 10^{5} \mathrm{Scm}^{-1}$ for fluorine-intercalated PAN fiber, pitch fiber and vapor grown carbon fiber (VGCF), respectively. The stability was in the order of the compounds of PAN fiber, pitch fiber and VGCF.
\end{abstract}

KEYWORDS: Graphite intercalation compound, Fluorine, Carbon fiber, Electrical conductivity

\section{Introduction}

One of the interesting properties of graphite intercalation compound (GIC) is the high in-plane electrical conductivity, which is close to those of metals when GIC is synthesized from a highly graphitized material. Among many known GICs, fluorine-graphite intercalation compound, $C_{x} F$, occupies a unique position because of the nature of chemical bond between host and quest, i.e. the C-F bond varies from the ionic to semi-ionic with increasing fluorine content in $\mathrm{C}_{\mathrm{x}} \mathrm{F}$. Fluorine atom with the highest electronegativity easily makes a stable $\mathrm{C}$-F bond by intercalation into graphite. The stability of $\mathrm{C}_{\mathrm{x}} \mathrm{F}$ increases with increasing covalent nature of $\mathrm{C}-\mathrm{F}$ bond. Carbon fiber is a very good host material for making use of the high conductivity of GIC. The present paper reports the synthesis of fluorine-GICs from several carbon fibers and their electrical conductivities and stability, including the structure analysis.

\section{Experimental}

$\mathrm{C}_{\mathrm{x}} \mathrm{F}$ samples were prepared at room temperature from PAN- and pitch-based carbon fibers graphitized at $2800^{\circ} \mathrm{C}$, vapor-grown carbon fiber (VGCF) graphitized at $2950^{\circ} \mathrm{C}$, natural graphite powder and highly oriented pyrolytic graphite (HOPG) in the presence of a fluoride such as $\mathrm{LiF}, \mathrm{MgF}_{2}, \mathrm{AgF}$ or $\mathrm{HF}$. The precise synthetic conditions were described in the literatures ${ }^{1)-3}$. Powder and HOPG samples were subjected to the structure analysis by $\mathrm{X}$-ray and electron diffractometries. The composition was calculated by weight increase and stage number was determined from $c$-axis repeat distance, $I_{c}$.

The electrical conductivity was measured by 4 points DC method at room temperature. The chemical bond between carbon and fluorine was evaluated by XPS (ESCA). 


\section{Results and Discussion}

\subsection{Composition and Stage Number}

The composition and stage number of $\mathrm{C}_{\mathrm{x}} \mathrm{F}$ depend on crystallinity of carbon fiber, oxidative ability of a fluoride used as a catalyst and fluorine pressure. Intercalation of fluorine is favored in the order of $\mathrm{AgF}$, $\mathrm{LiF}$ and $\mathrm{MgF}_{2}$ or $\mathrm{AlF}_{3}$ when they are used as a catalyst. A trace of $\mathrm{HF}$ coexisting in a nickel reactor was $0.01 \%$ or less when the purification of the reactor was repeated 4 or 5 times by rotary and diffusion pumps ${ }^{2)-4)}$, and approximately 0.1 to $0.4 \%$ when only a rotary pump was used $^{1)}$. A trace of $\mathrm{HF}$ ranging from 0.1 to $0.4 \%$

Table 1 Stage and composition of $\mathrm{C}_{\mathrm{x}} \mathrm{F}$ prepared from pitch-based carbon fiber

\begin{tabular}{|c|c|c|c|c|}
\hline stage & $I_{c} / \AA$ & composition & F content/wt $\%$ & $\mathrm{~F}_{2}$ pressure/atm \\
\hline \multirow{3}{*}{4} & $16.1_{4}$ & $\mathrm{C}_{16.7} \mathrm{~F}$ & 8.7 & 0.5 \\
\hline & $16.0_{7}$ & $\mathrm{C}_{13.5} \mathrm{~F}$ & 10.5 & 0.1 \\
\hline & $15.3_{2}$ & $\mathrm{C}_{13.1} \mathrm{~F}$ & 10.8 & 0.5 \\
\hline \multirow{8}{*}{3} & $12.6_{5}$ & $\mathrm{C}_{11.2} \mathrm{~F}$ & 12.4 & 0.5 \\
\hline & $12.7_{7}$ & $\mathrm{C}_{11.0} \mathrm{~F}$ & 12.6 & 0.5 \\
\hline & $12.6_{5}$ & $\mathrm{C}_{10.8} \mathrm{~F}$ & 12.7 & 1.0 \\
\hline & $12.8_{3}$ & $\mathrm{C}_{10.2} \mathrm{~F}$ & 13.4 & 0.3 \\
\hline & $12.6_{7}$ & $\mathrm{C}_{10.2} \mathrm{~F}$ & 13.4 & 0.5 \\
\hline & $12.8_{2}$ & $\mathrm{C}_{9.9} \mathrm{~F}$ & 13.8 & 0.4 \\
\hline & $12.7_{8}$ & $\mathrm{C}_{9.5} \mathrm{~F}$ & 14.2 & 0.4 \\
\hline & $12.7_{2}$ & $\mathrm{C}_{9.4} \mathrm{~F}$ & 14.4 & 0.4 \\
\hline \multirow{3}{*}{$2+3$} & & $\mathrm{C}_{8.8} \mathrm{~F}$ & 15.3 & 0.5 \\
\hline & & $\mathrm{C}_{8.0} \mathrm{~F}$ & 16.5 & 1.2 \\
\hline & & $\mathrm{C}_{7.9} \mathrm{~F}$ & 16.7 & 1.0 \\
\hline \multirow{14}{*}{2} & $9.3_{3}$ & $\mathrm{C}_{7.5} \mathrm{~F}$ & 17.4 & 1.0 \\
\hline & $9.2_{9}$ & $\mathrm{C}_{7.4} \mathrm{~F}$ & 17.6 & 1.0 \\
\hline & $9.3_{4}$ & $\mathrm{C}_{7.2} \mathrm{~F}$ & 18.0 & 1.0 \\
\hline & $9.3_{6}$ & $\mathrm{C}_{7.1} \mathrm{~F}$ & 18.2 & 1.4 \\
\hline & $9.3_{3}$ & $\mathrm{C}_{6.6} \mathrm{~F}$ & 19.4 & 1.9 \\
\hline & $9.3_{0}$ & $\mathrm{C}_{6.6} \mathrm{~F}$ & 19.4 & 1.0 \\
\hline & $9.3_{4}$ & $\mathrm{C}_{6.6} \mathrm{~F}$ & 19.4 & 1.0 \\
\hline & $9.3_{3}$ & $\mathrm{C}_{6.5} \mathrm{~F}$ & 19.5 & 1.0 \\
\hline & $9.3_{7}$ & $\mathrm{C}_{6.5} \mathrm{~F}$ & 19.6 & 1.0 \\
\hline & $9.3_{5}$ & $\mathrm{C}_{6.2} \mathrm{~F}$ & 20.4 & 1.0 \\
\hline & $9.2_{8}$ & $\mathrm{C}_{5.9} \mathrm{~F}$ & 21.1 & 1.0 \\
\hline & $9.3_{2}$ & $\mathrm{C}_{5.5} \mathrm{~F}$ & 22.2 & 1.0 \\
\hline & $9.3_{4}$ & $\mathrm{C}_{5.3} \mathrm{~F}$ & 23.0 & 1.0 \\
\hline & $9.3_{6}$ & $\mathrm{C}_{4.9} \mathrm{~F}$ & 24.3 & 1.0 \\
\hline
\end{tabular}

easily catalyzes the fluorine intercalation in graphite, while the effect of HF contamination on fluorine intercalation is almost neglected in the former case.

Fluorine intercalation increases with increasing crystallinity of a host carbon fiber, i.e. in the order of PAN fiber, pitch fiber and VGCF. Table 1 shows the composition and stage number of $\mathrm{CxF}$ samples prepared from pitch fiber in the presence of $\mathrm{AgF}^{4)}$. With increasing fluorine pressure, stage number varied from 4 to 2 and fluorine content was increased from $\mathrm{C}_{16.7} \mathrm{~F}$ to $\mathrm{C}_{4.9} \mathrm{~F}$. Mainly stage 3 compounds were obtained from PAN fibber ${ }^{1)}$. No stage 1 compound was prepared in a highly purified system without HF. Fluorine intercalation is much easier in case of VGCF. When HF contamination was $0.1 \%$ or less, stage $3, \mathrm{C}_{9} \mathrm{~F}$ to $\mathrm{C}_{12} \mathrm{~F}$ samples were obtained under coexistence of $\mathrm{CuF}_{2}^{2)}$ and stage 1 to 2 samples with composition of $\mathrm{C}_{4.0} \mathrm{~F}$ to $\mathrm{C}_{6.0} \mathrm{~F}$ were synthesized in the presence of $\mathrm{AgF}$. When 0.1 to $0.4 \% \mathrm{HF}$ was present in the reaction system with $\mathrm{AgF}$, stage $1, \mathrm{C}_{2.9} \mathrm{~F}$ to $\mathrm{C}_{3.6} \mathrm{~F}$ were obtained. These data are given in Table 2 with $\mathrm{X}$-ray data. To obtain $\mathrm{C}_{2} \mathrm{~F}-\mathrm{C}_{2.5} \mathrm{~F}$, it is necessary to use gaseous and liquid $\mathrm{HF}$.

\subsection{Structure and Chemical Bond}

The $c$-axis and in-plane structures were investigated by using HOPG and powder samples. In the X-ray diffractogram of stage 1 sample prepared from HOPG, a very strong (002) diffraction line and very weak (001), (003) and (004) lines were observed. Thus the stage 1 phase has a large repeat distance of 10.5 to $12 \AA$,

Table 2 Composition, stage number and $I_{c}$ values of $C_{x} F$ samples prepared form vapor-grown carbon fiber

\begin{tabular}{ccc}
\hline Composition & Stage & $\mathrm{I}_{\mathrm{c}} / \AA$ \\
\hline $\mathrm{C}_{6.0} \mathrm{~F}$ & 2 & 9.22 \\
$\mathrm{C}_{5.8} \mathrm{~F}$ & 2 & 9.29 \\
$\mathrm{C}_{5.2} \mathrm{~F}$ & 2 & 9.38 \\
$\mathrm{C}_{4.5} \mathrm{~F}$ & $1+(2)$ & 5.16 \\
$\mathrm{C}_{4.1} \mathrm{~F}$ & $1+(2)$ & 5.18 \\
$\mathrm{C}_{4.1} \mathrm{~F}$ & 1 & 5.27 \\
$\mathrm{C}_{4.0} \mathrm{~F}$ & 1 & 5.32 \\
$\mathrm{C}_{3.6} \mathrm{~F}$ & 1 & 5.35 \\
$\mathrm{C}_{3.5} \mathrm{~F}$ & 1 & 5.52 \\
$\mathrm{C}_{3.0} \mathrm{~F}$ & 1 & 5.55 \\
$\mathrm{C}_{2.9} \mathrm{~F}$ & 1 & 5.65 \\
\hline
\end{tabular}


which has been interpreted in terms of formation of a biintercalation phase consisting of almost ionically and semi-ionically bonded fluorine atoms ${ }^{3)}$. The in-plane structure was determined by $\mathrm{X}$-ray and electron diffraction. Debye-Scherrer and electron diffraction measurements of powder samples revealed that stage 2 and 3 samples belonged to a hexagonal system with an in-plane superlattice $a_{0}=2 a_{g}$, but stage 1 phase showed no superlattice ${ }^{3)}$.

$\mathrm{X}$-ray diffraction patterns of fiber samples are similar to those of natural graphite flake and powder samples. At the early stage of intercalation, the diffraction lines with highest intensity for stage 2 and 3 samples are the (003) and (004) lines, respectively. However, the intensity of (002) and (003) lines became stronger than that of (003) and (004) lines at the same stage with increasing fluorine intercalation. Generally an intercalated fluorine is situated at the center of two carbon sheets when $(00 n+1)$ line ( $n$ : stage number) has the highest intensity. With increasing $\mathrm{C}-\mathrm{F}$ bond strength, i.e. as the position of fluorine atom deviates from the center of two carbon sheets, the intensity of (00n) diffraction line gradually increases, accompanied by decrease in the intensity of $(00 n+1)$ line. Such kind of change in the intensity of diffraction lines indicates the increase in the covalency of C-F bond. In the stage 2 compounds prepared from VGCF (given in Table 2), the (002) diffraction lines showed the highest intensity. The stage 1 compounds had only one strong (001) lines indicating the semi-ionic $\mathrm{C}$-F bond. A large $c$-axis repeat distance of 10.5 to $12 \AA$ was not observed in the stage 1 compounds prepared from VGCF. The $I_{c}$ values of the stage 1 ranged from 5.1 to $5.7 \AA$. This may be because of the lower crystallinity of VGCF samples than that of HOPG ones.

The results of XPS study coincide with those obtained by X-ray diffraction. As the surface of fiber compound was strongly fluorinated, a shifted $\mathrm{C}_{1 \mathrm{~s}}$ peak was found at $289 \mathrm{eV}$ with a main peak at $284.3 \mathrm{eV}^{2}$. $F_{1 s}$ peak was also observed at a high binding energy, $688 \mathrm{eV}^{2}$. These binding energies indicate that fluorine is almost covalently bonded to carbon around the surface area of a fiber. However, the inside of the fiber possessed the more ionic $\mathrm{C}-\mathrm{F}$ bond. Stage $3, \mathrm{C}_{10.1} \mathrm{~F}$ prepared from VGCF showed $C_{1 \mathrm{~s}}$ and $F_{1 s}$ peaks at 284.3 $\mathrm{eV}$ and $685.8 \mathrm{eV}$, respectively. In stage $2, \mathrm{C}_{5.2} \mathrm{~F}$ having

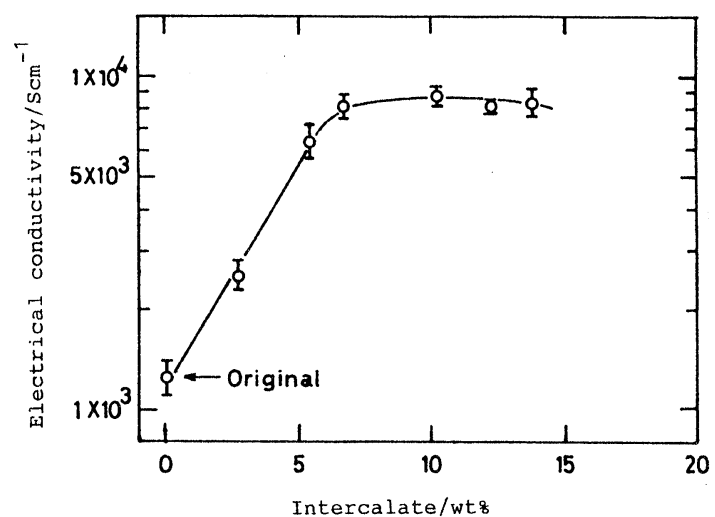

Fig. 1 Electrical conductivity of PAN-based carbon fiber intercalated by fluorine at room temperature

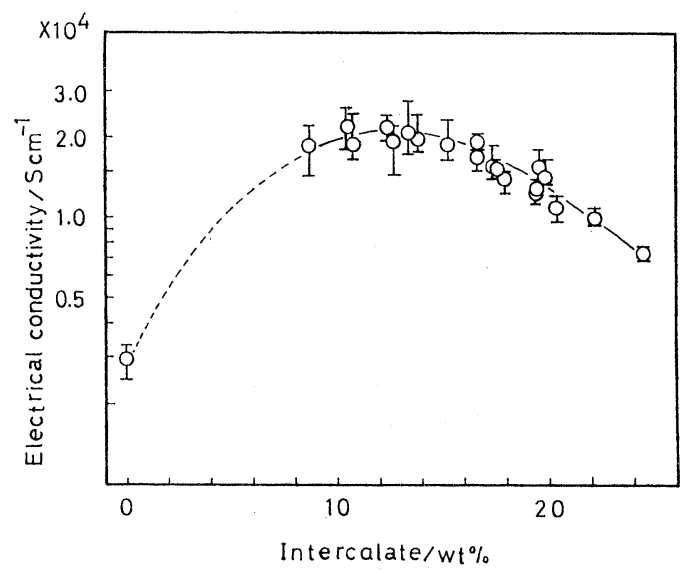

Fig. 2 Electrical conductivity of $\mathrm{C}_{\mathrm{x}} \mathrm{F}$ prepared from pitch-based carbon fiber at room temperature

a higher fluorine content, a strong $C_{1 s}$ peak was observed at $284.1 \mathrm{eV}$ with a small shoulder located at $287.3 \mathrm{eV} . F_{1 \mathrm{~s}}$ appeared at a slightly higher binding energy, $686.0 \mathrm{eV}$. These data indicate that $\mathrm{C}-\mathrm{F}$ bond is strengthened with increasing fluorine content, and some covalency is included in C-F bond even in stage 2 and 3 samples.

\subsection{Electrical Conductivity and Stability}

The electrical conductivity of carbon fiber increased by fluorine intercalation as shown in Figs. 1 and 2. The conductivity increases at first with increasing number of positive holes created by electron transfer from carbon to intercalated fluorine. After reaching the maximum conductivity, the conductivity gradually 


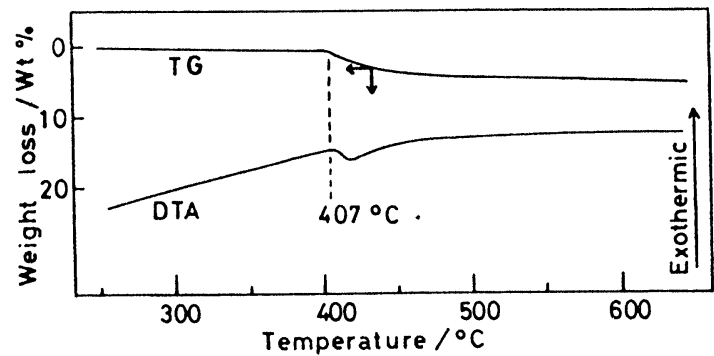

Fig. 3 DTA and TG curves for stage $3+4 \quad \mathrm{C}_{9.9} \mathrm{~F}$ prepared from PAN-based carbon fiber in $\mathrm{N}_{2}$ atmosphere

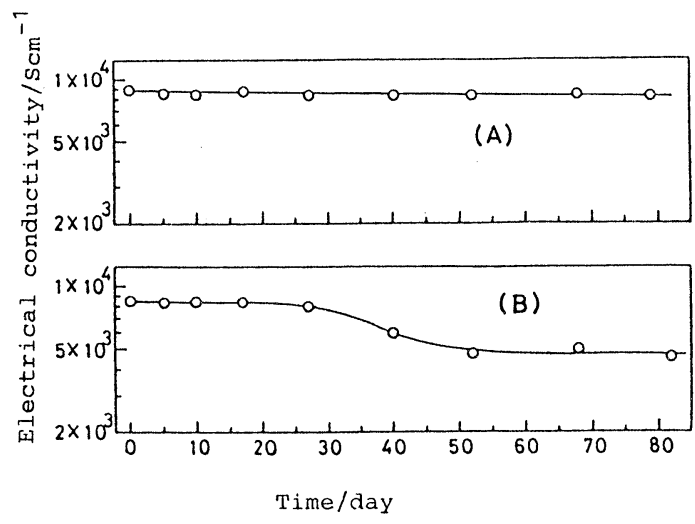

Fig. 4 Change in the electrical conductivity of PANbased carbon fiber intercalated by fluorine in air (A) and in water (B)

decreases with decreasing charge transfer coefficient and carrier scattering by lattice vibration. The maximum conductivity values were $(8-9) \times 10^{3} \mathrm{Scm}^{-1}$ for PAN fiber in the range of 7 to $14 \mathrm{wt} \%$ fluorine ${ }^{1)}$, and 2.4 $\times 10^{4} \mathrm{Scm}^{-1}$ for pitch fiber at stage $3^{4)}$. These values were 7 and 8 times those of pristine fibers. VGCF showed a much higher conductivity, $1.1 \times 10^{5} \mathrm{Scm}^{-1}$ which is 8.5 times that of pristine $\mathrm{VGCF}^{2)}$.

The stability of fluorine-intercalated PAN fiber was investigated by thermal analysis (DTA and TG) and conductivity change in air and water. DTA and TG showed that the decomposition of fluorine-intercalated PAN fiber started at $407^{\circ} \mathrm{C}$ as shown in Fig. $3^{3)}$. Fig. 4 shows the change of the conductivities in air and in water. The decrease in the conductivity in air was only $7 \%$ after about 80 days. Even in water, it remained almost unchanged for 25 days, then gradually decreased to half of the conductivity just after the preparation.

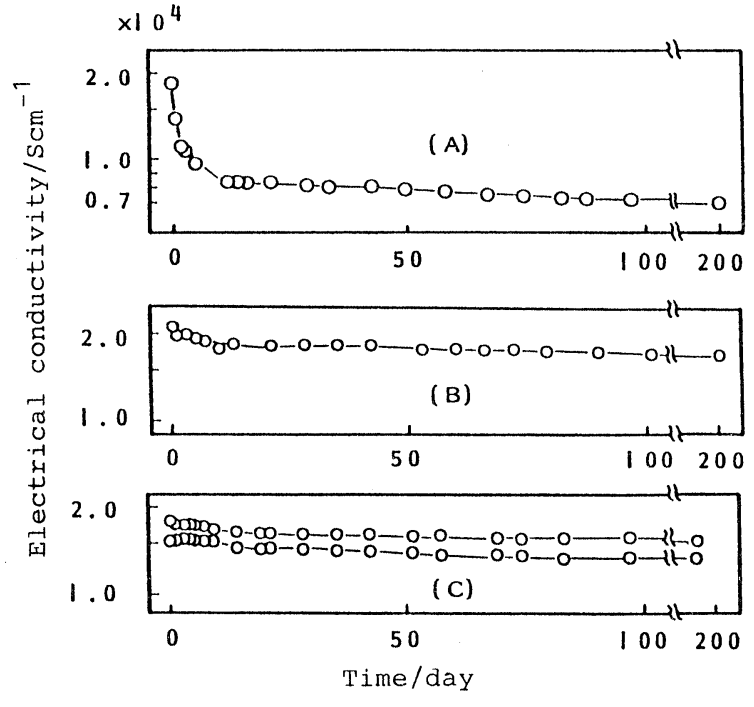

Fig. 5 Change in the electrical conductivity of $C_{x} F$ prepared from pitch-based carbon fiber in air: (A): stage $4, \mathrm{C}_{16.7} \mathrm{~F},(\mathrm{~B})$ : stage $2+3, \mathrm{C}_{8.8} \mathrm{~F},(\mathrm{C})$ : stage $2, \mathrm{C}_{6.5} \mathrm{~F}$

The conductivity change of fluorine-intercalated pitch fiber in air is shown in Fig. $5^{4)}$. With increasing fluorine content, i.e. with decreasing stage number, the stability of the compounds increased probably because of the increase in the covalency of C-F bond. Decrease in the conductivity was observed mainly within 20 days after synthesis. After that the decrease of the conductivity was small. The conductivity decrease during 200 days was $61.6,20.0$ and $13.0 \%$ for stage $4, \mathrm{C}_{16.7} \mathrm{~F}$, stage $2+3$, $\mathrm{C}_{8.8} \mathrm{~F}$ and stage $2, \mathrm{C}_{6.5} \mathrm{~F}$, respectively. In proportion to the conductivity decrease, the weight of the compounds decreased by 3 to $4 \mathrm{wt} \%$ during 100 days, and at the same time, the (002) diffraction peak of carbon slightly appeared in the X-ray diffraction pattern. DTA and TG analysis indicated that the decomposition to a higher stage started at about $130^{\circ} \mathrm{C}$. On the other hand, fluorine-intercalated VGCF was less stable than the above-mentioned two compounds, decomposing to carbon in air after 1 month.

There would be several factors influencing the stability of fluorine-intercalated carbon fibers. They may be the regularity of in-plane orientation of fluorine, chemical interaction between carbon and fluorine and structures of host carbon fibers. With increasing fluorine intercalation, the chemical bond between 
carbon and fluorine gradually changes from ionic to semi-ionic, i.e. the covalency of $\mathrm{C}-\mathrm{F}$ bond increases. According to the change of chemical bond from ionic to semi-ionic, intercalated fluorines tend to take a regular orientation between two carbon sheets. These effects increase the stability of $\mathrm{C}_{\mathrm{x}} \mathrm{F}$. The crystallinity increases in the order of PAN fiber, pitch fiber and VGCF. Experimental results revealed that stability decreased with increasing crystallinity of host fibers. With increasing crystallinity of hosts, not only intercalation but also deintercalation seems to be easier.

\section{References}

1) T. Nakajima, M. Kawaguchi and N. Watanabe, Synthetic Metals 7, 117 (1983).

2) T. Nakajima, N. Watanabe, I. Kameda and M. Endo, Carbon 24, 343 (1985).

3) T. Nakajima, M. Molinier and M. Motoyama, Carbon 29, 429 (1991).

4) T. Nakajima, T. Ino, N. Watanabe and H. Takenaka, Carbon 26, 397 (1988). 